doi:10.1017/S1474745617000088

\title{
The BRICS: A Very Short Introduction
}

by Andrew F. Cooper

Oxford University Press, 2016

The BRICS (a group formed by Brazil, Russia, India, China and more recently, South Africa $^{1}$ ) appears likely to be the archetype of twenty-first century's clusters of governments at the international level. ${ }^{2}$ The acronym dates back to 2001 by the US multinational finance company, Goldman Sachs, as a group of fast-growing, largely unrelated countries. ${ }^{3}$ Yet, the BRICS constitutes today an (informal) organization of countries seeking to build together a platform of cooperation in a large array of areas, while downplaying several differences between their members.

It is difficult, and perhaps futile, to ascertain the exact date of birth of the BRICS as an organization. Since June $2009,{ }^{4}$ the BRICS has held eight summits, with the last one having been held at Goa, India, in October 2016. It is through this 'summitry' approach that the leaders of the five nations have addressed the most pressing global economic issues, and agreed to enhanced cooperation in key areas such as trade, health, education, finance, agriculture, communication, and labour.

The book The BRICS: A Very Short Introduction, by Professor Andrew F. Cooper, represents the most comprehensive book on the BRICS to date. Its 116 pages provide a succinct, but detailed, recount of how the BRICS came about, its historical determinants, its original goals, and the more ambitious agenda as new summits take place. With a great deal of optimism, but warning against naivety, Professor Cooper offers the analytical framework and perspective from which to study this new 'phenomenon' in international politics.

In 'Framing the BRICS' (Chapter 1), Professor Cooper lays out the origins and reason d'être of the BRICS. By way of comparison, the book provides an assessment of similar clusters of countries such as the MINT, ${ }^{5}$ CIVETS, ${ }^{6}$ the N11, ${ }^{7}$ or the MIST. ${ }^{8}$ Professor Cooper explains that what makes the BRICS different is, in his own words, 'the ongoing transformation of the original descriptive content into diplomatic practice' (p. 4). The political and economic importance of the BRICS members makes this particular cluster special: it encompasses the second economic power in the world (China); the two most populous countries (China and India); and two members of the United Nations Security Council (China and Russia). The appetite 'for recognition of their enhanced status both in the West and in the global south', has set the BRICS up as the counterpoint to the G7

1 South Africa joined the BRICS in September 2010.

2 I refer to the BRICS in the singular because Professor Cooper sees it as a group of countries with 'distinct institutional personality' (p. 50).

3 See Jim O’Neill, Building Better Global Economic BRICs, Goldman Sachs, Paper No. 66, 30 November 2001, available at http://www.goldmansachs.com/our-thinking/archive/archive-pdfs/build-better-brics.pdf.

$4 \mathrm{It}$ is said that the BRICS was formalized at first meeting of foreign ministers held on the sidelines of the United Nations General Assembly in September 2006.

5 The MINT comprise Mexico, Indonesia, Nigeri,a and Turkey.

6 The CIVETS are Colombia, Indonesia, Vietnam, Egypt, Turkey, and South Africa.

7 The N11 consist of Bangladesh, Egypt, Indonesia, Iran, Mexico, Nigeria, Pakistan, the Philippines, Turkey, South Korea, and Vietnam.

8 The MIST are Mexico, Indonesia, South Korea, and Turkey. 
and as the strongest representation of the developing countries. This chapter thus takes stock of the place of the BRICS in the international arena.

'A Contested Invention' (Chapter 2) describes the actual establishment of the BRICS. Starting as a convenient shorthand by Goldman Sachs to name a number of fastgrowing emerging countries outside the G7, ${ }^{9}$ the BRICS is a function of earlier attempts at bringing together at least some of its members. Examples of these are the IBSA Business Council (India, Brazil, and South Africa) or the RIC (Russia, India, and China). Professor Cooper analyses these initiatives, as well as the early cooperation meetings between the G7 and today's BRICS. The book also gives an account of the considerations that led to the emancipation of the BRIC (without South Africa, at the time) from the G7 in order to build its own forum. In 2009, the BRIC held its summit at Yekaterinburg, Russia, with a distinct institutional personality.

'A Historical Departure' (Chapter 3) explains the institutional and geo-political determinants that caused the BRICS to move away from the G7. The BRICS was faced with the choice of portraying itself as the representative of the Global South or as a group that uses the growing weight and capacity of its members to advance its own interests. Professor Cooper pointedly observes that the BRICS appeared to choose the latter as they do 'not assert the need to change the international system' to address the concerns of the developing countries. Rather, 'they are contesting the international order on the basis of their rising economic and political power' (p. 38). Professor Cooper thus presents the BRICS as a group rooted in several South-South initiatives, but which somehow departs from South-South demands of reshuffling the international order.

'Hanging Together' (Chapter 4) provides a vivid and insightful recount of the political tensions and differences that BRICS members have to overcome in order to advance the BRICS agenda. Professor Cooper recognizes the rivalries over borders between China and India, energy-related concerns, the reform of the United Nations Security Council, as well as trade- and investment-restrictive measures among the BRICS members, especially against China. The BRICS members have also had to be flexible and allow individual members to engage with other countries in bilateral pacts. At the same time, the BRICS maintains a cohesive attitude in several other key areas for instance, they all share a sense of historical grievance. In the aftermath of the 2008 global crisis, the BRICS leaders put the blame on the irresponsible policies by the developed countries. In addition, Professor Cooper ably explains China's lowprofile role as exerting its influence 'behind the scenes', which contributes to the cohesion of the cluster. Accordingly, it is rather the informal (or flexible) institutional setting that allows the BRICS to group together countries with dissimilar and often competing interests. Or, as Professor Cooper puts it, the BRICS members have made strides to play up the similarities and shared goals, and play down any differences.

In 'Building the New Development Bank' (Chapter 5), Professor Cooper describes the process that led up to the greatest institutional outcome of the BRICS to this day: the New Development Bank (NDB). The stated objective of the NDB is to fund infrastructure projects in developing countries both within and outside the BRICS area. The

9 Professor Cooper explains the particularities of Russia, not as a fast-growing or emerging country, but as a country with other key, geo-political attributes to be considered as a relevant player in the international order. 
book provides an eloquent recount of events that led up to the creation of the NDB. For instance, it explains that prior to the NDB, each development bank or agency of individual BRICS members had different financing programmes to support projects in other developing countries. BRICS members decided, not without reluctance from some of them, to turn these national programmes into a collective initiative as an alternative to the existing international financial institutions 'to mobilise finance for infrastructure in the developing world' (p. 69). This initiative faced several hindrances along the way: first, the issue of contributions to the bank by each BRICS member, which brought to light the imbalance in capacity among the membership; second, the question of the seat of the NDB, with China raising its voice to secure the seat in Shanghai; and, third, the mode of governance of the NDB. On balance, the compromise reached by the BRICS members accommodated to a certain extent their interests, while seeking to do away, at least formally, with the perceived flaws of the existing international financial institutions, notably the uneven weight of their Members in the decision-making process.

'BRICS as the Recognition of States, Not Societies' (Chapter 6) explores the dynamics of the BRICS as a group of governments where no leader stands out or prevails over others. Moreover, the BRICS remains a state-centric organization. Professor Cooper looks into the lack of openness of the BRICS to civil society in the face of the increased presence of civil society groups at the BRICS summits demanding more access to the BRICS debate. The book describes a number of BRICS platforms such as the BRICS Business Council; the BRICS Think Tank Council; and the BRICS Trade Union Forum. However, many of these initiatives are still controlled directly or indirectly by the governments of the BRICS members. Professor Cooper thus emphasizes the scarce participation of the civil society in the BRICS activities but remains optimistic that 'the opportunity has opened up to increase the diversity of participation as the BRICS moves forward' (p. 102).

In 'The Staying Power of the BRICS' (Chapter 7), the book enquires into the future prospects of the BRICS. On the one hand, it identifies certain weaknesses; for instance, growth prospects are no longer as promising as they were 2001 when Goldman Sachs likened the acronym with economic prosperity. Moreover, the diplomatic interactions between the members are likely to be a challenge in view of their stark differences in the international arena. For instance, Professor Cooper points to certain issues of potential contention among the BRICS countries, such as Russia's, but not others', incentive to have a more confrontational stance vis-à-vis western countries. On the other hand, the BRICS members have built undeniable links. Trade flows within the BRICS have skyrocketed over the past five years. Similarly, the flexibility or informality on which the BRICS is built allows faster and more effective responses to global shocks. As the BRICS has gained a distinct personality in international politics, its members may seek to preserve its importance as a counterweight to the G7. In the words of Professor Cooper, '[f]or all of their differences, each member benefits from the establishment of an informal institution of their own' (pp. 114 and 115).

In brief, the BRICS as a group of countries is gaining influence in international politics. It has moved away from traditional rule-making at the international level by adopting, what Professor Cooper calls informality and improvisation over formal binding modes of operation' (p. 102). The BRICS: A Very Short Introduction walks the reader through this unfinished, but nonetheless exciting, project from a variety of 
angles. The book provides a succinct recount of the political and diplomatic determinants that have shaped the BRICS to this day. Of course, in just 116 pages it seems impossible to provide every single detail of the specific arrangements and agreements that the BRICS countries have reached. For instance, the book does not explain in depth the results of the BRICS summits as reflected in the presidential declarations adopted in each of these summits.

As most books addressing current political issues, The BRICS: A Very Short Introduction runs the risk of becoming outdated in the short- to medium-term. However, in this first edition, Professor Cooper has provided an excellent historical and conceptual basis on which to continue the study of future developments of the BRICS as a political phenomenon in the international arena. Although this is not intended to be a law book, Professor Cooper may even consider to add in the future some analysis of the emerging 'law of the BRICS' should the BRICS countries choose to create institutions with fixed rules. For the time being, however, BRICS countries have, except for the creation of the NDB, maintained the BRICS on the political level without pre-established rules.

In brief, this book constitutes a 'must' for those who wish to learn about this gamechanger in international political science. As the BRICS develops, other books may appear. But, as of today, this is the book of reference in the field.

Christian Vidal-León, ACWL \& Mandela Institute, University of the Witwatersrand, South Africa 